\title{
Application of Interpolation Algorithm in Data Processing of the Advanced Multi-electrode Electrical Sounding Method to Determine Saturation Line in the Earth Dam
}

\author{
Vu Duc Minh* \\ VNU University of Science, 334 Nguyen Trai, Thanh Xuan, Hanoi, Vietnam
}

Received 22 July 2016

Revised 26 August 2016; Accepted 20 September 2016

\begin{abstract}
Improving the efficiency of data processing of the Advanced Multi-electrode Electrical Sounding method is a practical work and necessary. Previously, we have used the Advanced Multi-electrode Electrical Sounding method to locate saturation line in the earth dam with the positive results. However, one of the data processing steps only stopped at Trendline method, hence the difference to the results measured by the Pizomet systems is good but a lot to be desired. In this paper, we present several new results determining the saturation line of earth dam in Dong Mo, Ha Noi by the Advanced Multi-electrode Electrical Sounding method using the interpolation method and the second derivative during data processing. The results are more accurate than the previous results, with the biggest error of $5.1 \%$ compared to the results determined by Pizomet system.
\end{abstract}

Keywords: Trendline, interpolation method, second derivative, Polyfit, error.

\section{Rationale}

With the aim of helping the Multi-electrode Electrical Sounding method achieve greater efficiency in environmental research, the Advanced Multi-electrode Electrical Sounding method (AMES) has been proposed on the basis of developing and integrating the advantages of the traditional Multielectrode Electrical Sounding method and the Improved Electrical Sounding methods [1].

Identifying the location of saturation line in the dam at a typical moment of lake water level is an essential job, hence this is the basis of assessment and analysis of the seepage in the dam, as well as evaluation of the stability and safety of the dam.

We have used AMES method to locate the saturation line of the dam in Dong Mo and collected positive results [2]. However, the method of determining saturation only stopped at Trendline method, hence the difference to the results measured by the Pizomet systems is good but a lot to be desired.

* Tel.: 84-914658586

Email: vducminh56@gmail.com 
In this paper, we introduce a number of new test results obtained from studying the possibility of identifying the saturation line of the earth dam by the Advanced Multi-electrode Electrical Sounding method using the interpolation method and the second derivative function during data processing.

\section{Some interpolation methods}

\subsection{Polyfit interpolation method [3, 4]}

Usually in a number of fields such as economy, the quantity survey is not usually in the form of continuous function, which is a table of discrete values. The mathematical analysis methods often calculated with the function given by the formula, so cannot be directly applied to the study of the form of discrete function like this. Also when we know that the quantity y is a function of the quantity $x$, i.e. $y=f(x)$, but we do not know the expression $f(x)$, but only know some of the values that correspond to the values of $\mathrm{x}$ at the point $\mathrm{x}_{\mathrm{i}}$ as in the following table:

\begin{tabular}{lllllll}
\hline $\mathrm{x}_{\mathrm{i}}$ & $\mathrm{x}_{0}$ & $\mathrm{x}_{1}$ & $\mathrm{x}_{2}$ & $\ldots$ & $\mathrm{x}_{\mathrm{n}-1}$ & $\mathrm{x}_{\mathrm{n}}$ \\
\hline $\mathrm{y}_{\mathrm{i}}$ & $\mathrm{y}_{0}$ & $\mathrm{y}_{1}$ & $\mathrm{y}_{2}$ & $\ldots$ & $\mathrm{y}_{\mathrm{n}-1}$ & $\mathrm{y}_{\mathrm{n}}$ \\
\hline
\end{tabular}

Usually $\mathrm{x}_{0}<\mathrm{x}_{1}<\mathrm{x}_{2}<\ldots<\mathrm{x}_{\mathrm{n}}$ and these points can be distributed evenly or not. Although we only know the values of $y$ at the landmark $x_{i}$, but in many cases we need to calculate the values of $y$ at the other positions of $\mathrm{x}$.

Interpolation problem is the problem of finding an approximate value of $y$ at the point between the values of $\mathrm{x}$ is not in the table above.

Interpolation problem can now speak in more detail as follows:

For a sample of $\mathrm{n}+1$ pairs observed the known values of $\mathrm{x}$ and $\mathrm{y}:\left(\mathrm{x}_{0}, \mathrm{y}_{0}\right),\left(\mathrm{x}_{1}, \mathrm{y}_{1}\right) \ldots,\left(\mathrm{x}_{\mathrm{n}}, \mathrm{y}_{\mathrm{n}}\right)$. Let's build a polynomial of degree $m \leq n$

$$
\begin{aligned}
& \mathrm{p}_{\mathrm{m}}(\mathrm{x})=\mathrm{a}_{0}+\mathrm{a}_{1} \mathrm{x}^{1}+\ldots+\mathrm{a}_{\mathrm{m}-1} \mathrm{x}^{\mathrm{m}-1}+\mathrm{a}_{\mathrm{m}} \mathrm{x}^{\mathrm{m}} \\
& \text { that } \mathrm{p}_{\mathrm{m}}\left(\mathrm{x}_{\mathrm{i}}\right)=\mathrm{y}_{\mathrm{i}}, \mathrm{i}=0,1, \ldots, \mathrm{n}
\end{aligned}
$$

They call this is polynomial interpolation problem, and polynomial $\mathrm{p}_{\mathrm{m}}(\mathrm{x})$ is called an interpolation polynomial.

Combining (1) and (2) we have

$$
\left(\begin{array}{c}
\mathrm{y}_{0} \\
\mathrm{y}_{1} \\
\cdot \\
\mathrm{y}_{\mathrm{n}}
\end{array}\right)=\left[\begin{array}{ccccc}
1 & \mathrm{x}_{0} & \mathrm{x}_{0}^{2} & \ldots & \mathrm{x}_{0}^{\mathrm{n}} \\
1 & \mathrm{x}_{1} & \mathrm{x}_{1}^{2} & \ldots & \mathrm{x}_{1}^{\mathrm{n}} \\
\cdot & \cdot & \cdot & \ldots & \cdot \\
1 & \mathrm{x}_{\mathrm{n}} & \mathrm{x}_{\mathrm{n}}^{2} & \mathrm{x}_{\mathrm{n}}^{2} & \mathrm{x}_{\mathrm{n}}^{\mathrm{n}}
\end{array}\right]\left(\begin{array}{c}
\mathrm{a}_{0} \\
\mathrm{a}_{1} \\
\cdot \\
\mathrm{a}_{\mathrm{n}}
\end{array}\right)
$$

equation (3) has a unique solution for $\mathrm{a}_{\mathrm{i}}$, and so the polynomial $\mathrm{p}_{\mathrm{n}}(\mathrm{x})$ is uniquely identified. (If the equation (3) we get $a_{n} \neq 0$ then this polynomial of degree $n$, when $a_{n}=0$ of degree $<n$ ).

\subsection{Lagrange interpolation method [3]}

Suppose we have the observation points $\mathrm{x}_{0}, \mathrm{x}_{1}, \ldots, \mathrm{x}_{\mathrm{n}}$ with about equally or unequally, and a sequence of observed values $\mathrm{y}_{0}, \mathrm{y}_{1}, \ldots, \mathrm{y}_{\mathrm{n}}$. The first simple idea is to find an interpolation polynomial of degree $n$ (more precisely, of degree not exceeding $n$ ) such that the pairs $\left(x_{i}, y_{i}\right), i=0,1, \ldots, n$ there equal role. For example we find $\mathrm{p}_{\mathrm{n}}(\mathrm{x})$ has the form $\mathrm{p}_{\mathrm{n}}(\mathrm{x})=\mathrm{H}_{0}(\mathrm{x})+\mathrm{H}_{1}(\mathrm{x})+\ldots+\mathrm{H}_{\mathrm{n}}(\mathrm{x})$. The functions 
$\mathrm{H}_{\mathrm{i}}(\mathrm{x})$ are of degree not exceeding $\mathrm{n}$ and $\mathrm{H}_{\mathrm{i}}\left(\mathrm{x}_{\mathrm{i}}\right)=\mathrm{y}_{\mathrm{i}}, \mathrm{H}_{\mathrm{i}}\left(\mathrm{x}_{\mathrm{j}}\right)=0$ when $\mathrm{j} \neq \mathrm{i}$. To $\mathrm{H}_{\mathrm{i}}\left(\mathrm{x}_{\mathrm{j}}\right)=0$ when $\mathrm{j} \neq \mathrm{i}$ then $\mathrm{H}_{\mathrm{i}}(\mathrm{x})$ has the form:

$$
\mathrm{H}_{\mathrm{i}}(\mathrm{x})=\mathrm{K}(\mathrm{x})\left(\mathrm{x}-\mathrm{x}_{0}\right)\left(\mathrm{x}-\mathrm{x}_{1}\right) \ldots\left(\mathrm{x}-\mathrm{x}_{\mathrm{i}-1}\right)\left(\mathrm{x}-\mathrm{x}_{\mathrm{i}+1}\right) \ldots\left(\mathrm{x}-\mathrm{x}_{\mathrm{n}}\right)
$$

from conditions $H_{i}\left(x_{i}\right)=y_{i}$ have $K(x)\left(x-x_{0}\right)\left(x-x_{1}\right) \ldots\left(x-x_{i-1}\right)\left(x-x_{i+1}\right) \ldots\left(x-x_{n}\right)=y_{i}$ inferred

$$
\begin{aligned}
& \mathrm{K}(\mathrm{x})=\mathrm{y}_{\mathrm{i}} \frac{\left(\mathrm{x}-\mathrm{x}_{1}\right)\left(\mathrm{x}-\mathrm{x}_{2}\right) \ldots\left(\mathrm{x}-\mathrm{x}_{\mathrm{i}-1}\right)\left(\mathrm{x}-\mathrm{x}_{\mathrm{i}+1}\right) \ldots\left(\mathrm{x}-\mathrm{x}_{\mathrm{n}}\right)}{\left(\mathrm{x}_{\mathrm{i}}-\mathrm{x}_{1}\right)\left(\mathrm{x}_{\mathrm{i}}-\mathrm{x}_{2}\right) \ldots\left(\mathrm{x}_{\mathrm{i}}-\mathrm{x}_{\mathrm{i}-1}\right)\left(\mathrm{x}_{\mathrm{i}}-\mathrm{x}_{\mathrm{i}+1}\right) \ldots\left(\mathrm{x}_{\mathrm{i}}-\mathrm{x}_{\mathrm{n}}\right)} \\
& \text { If we sign } \quad \mathrm{L}_{\mathrm{i}}(\mathrm{x})=\frac{\left(\mathrm{x}-\mathrm{x}_{1}\right)\left(\mathrm{x}-\mathrm{x}_{2}\right) \ldots\left(\mathrm{x}-\mathrm{x}_{\mathrm{i}-1}\right)\left(\mathrm{x}-\mathrm{x}_{\mathrm{i}+1}\right) \ldots\left(\mathrm{x}-\mathrm{x}_{\mathrm{n}}\right)}{\left(\mathrm{x}_{\mathrm{i}}-\mathrm{x}_{1}\right)\left(\mathrm{x}_{\mathrm{i}}-\mathrm{x}_{2}\right) \ldots\left(\mathrm{x}_{\mathrm{i}}-\mathrm{x}_{\mathrm{i}-1}\right)\left(\mathrm{x}_{\mathrm{i}}-\mathrm{x}_{\mathrm{i}+1}\right) \ldots\left(\mathrm{x}_{\mathrm{i}}-\mathrm{x}_{\mathrm{n}}\right)}
\end{aligned}
$$

I noticed polynomial $\mathrm{L}_{\mathrm{i}}(\mathrm{x})$ has properties $\quad \mathrm{L}_{\mathrm{i}}\left(\mathrm{x}_{\mathrm{j}}\right)= \begin{cases}1 & j=i \\ 0 & j \neq i\end{cases}$

and the polynomial $\mathrm{p}_{\mathrm{n}}(\mathrm{x})$ has the form

$$
\mathrm{p}_{\mathrm{n}}(\mathrm{x})=\mathrm{y}_{0} \mathrm{~L}_{0}(\mathrm{x})+\mathrm{y}_{1} \mathrm{~L}_{1}(\mathrm{x})+\ldots+\mathrm{y}_{\mathrm{n}} \mathrm{L}_{\mathrm{n}}(\mathrm{x})
$$

\subsection{Spline interpolation method [3]}

In the previous section we have considered the problem using polynomial interpolation and as we have seen, the interpolation polynomials of degree is usually $n$, where $n+1$ is the number of observation points. We can order polynomial interpolation with smaller $\mathrm{m} \mathrm{n}$, but that they will only use observations based on $\mathrm{m}+1$ points is $\left(\mathrm{x}_{0}, \mathrm{y}_{0}\right),\left(\mathrm{x}_{1}, \mathrm{y}_{1}\right), \ldots,\left(\mathrm{x}_{\mathrm{m}}, \mathrm{y}_{\mathrm{m}}\right)$ and thus only interpolate the value of the function at the point $\mathrm{x} \in\left[\mathrm{x}_{0}, \mathrm{x}_{\mathrm{m}}\right]$. In a natural way, we think that if there are as many points observed our results as close to reality. However if using polynomial interpolation like we recently surveyed are not going to be like what we expected. For example, although the true form of the polynomial is level 3 , but if you use 5 points observation, we must calculate the polynomial coefficients level 4,10 points, we have to calculate with a polynomial of degree $9, \ldots$ meaning is the more points, the more we go beyond reality. Polynomial interpolation also has a downside too is the number of calculations required performance depends heavily on the size of the observed patterns.

Consider a sample of observations $\left(\mathrm{x}_{\mathrm{i}}, \mathrm{y}_{\mathrm{i}}\right), \mathrm{i}=0,1,2, \ldots, \mathrm{n}$ on the interval $[\mathrm{a}, \mathrm{b}]$, where $\mathrm{a}=\mathrm{x}_{0}<\mathrm{x}_{1}$ $<\ldots<\mathrm{x}_{\mathrm{n}}=\mathrm{b}$. According to the conventional interpolation, we have to find a polynomial of degree not exceeding $\mathrm{n}$ go through this observation point. This problem brought about defining $\mathrm{n}+1$ coefficients of the polynomial interpolation. With Spline interpolation, instead of defining a polynomial for both interval $[\mathrm{a}, \mathrm{b}]$, we define $\mathrm{n}$ polynomial $\mathrm{S}_{\mathrm{k}}(\mathrm{x}), \mathrm{k}=0,1,2, \ldots, \mathrm{n}-1$, each multi form of degree $\mathrm{m}$ (typically $\mathrm{m}=2$ or 3 ) and defined on the segment $\left[\mathrm{x}_{\mathrm{i}}, \mathrm{x}_{\mathrm{i}+1}\right]$, then stitch them together. We can expand the domain defined for each polynomial $S_{k}(x)$ by assigning it a value of 0 when $x \notin\left[x_{k}, x_{k+1}\right]$. Spline interpolation function level $\mathrm{m}$ will receive a composite polynomial on each piece you back together. Thus the value of Spline interpolation function on the segment $\left[x_{k}, x_{k+1}\right]$ is the value of the polynomial $S_{k}(x)$. Note that if $\mathrm{m}>1$, then the polynomials $\mathrm{S}_{\mathrm{k}}(\mathrm{x})$ is not a polynomial interpolation on the interval $\left[\mathrm{x}_{\mathrm{i}}, \mathrm{x}_{\mathrm{i}+1}\right]$, because the polynomial interpolation passing through 2 points to first-order polynomial. Of course, the polynomial must satisfy a number of conditions so that they are uniquely identified and reassembling them when I was a curve "smooth". Spline interpolation function must first be interpolated function, meaning that it passes through the observation points. It was found that in order to determine each child polynomial, we need to determine the $m+1$ coefficients. To determine these coefficients we should have binding $m+1$ conditions on them. The value of the polynomial at the two ends of the 
range has been identified, so that the two conditions. Missing several conditions that $m+1-2$. For example, with $\mathrm{m}=3$, then to identify the additional functions we need $2 \mathrm{n}$ Spline conditions. These conditions can be obtained by placing additional assumptions about the existence of derivative and value of them in markers.

\subsection{Test results to select the appropriate method}

We have established program with Matlab language to test the above interpolation method with data on an actual measurement line by AMES method.

The results of the method of Polyfit interpolation and Spline interpolation are better than the results of the method of Lagrange interpolation method. However, Spline interpolation method using the available functions in Matlab software and error values are preset should not be changed.

Therefore, we have chosen the method of Polyfit interpolation to apply processing data of measurement lines on Dong Mo dam.

\section{The results from determining the saturation line}

\subsection{Regional, research methods}

\subsubsection{Research Area}

To compare with previous results from determining the saturation line and the measured results by Pizomet to test the effectiveness of the method, the area we choose is still Dong Mo dam located in Son Tay, Ha Noi City. On the dam, Pizomet system is operating normally. Diagram of survey lines is at Pizomet A on Dong Mo dam [2].

\subsubsection{Research Methods}

Our method applied throughout the research process is the AMES method with the use of equipment system SuperSting R8 / IP (USA) [5] of the Department of the Earth Physics, Faculty of Physics, VNU University of Science.

At positions near Pizomet tube, analysing and identifying segments saturated permeable boundaries through the resistivity curve by preliminary analysis of the survey results on $2 \mathrm{D}$ images by software EarthImager 2D [6], while obtaining the depth of segments with a rapid change from high resistivity to low resistivity. Using our program with Matlab language with obtained data to establish approximate curve equation by Polyfit interpolation method, from there taking the second derivative to determine the inflection point of the resistivity curve. Using the inflection point value as the boundary to determine the saturation line.

\subsection{Specific results}

After conducting measurements, with the method of determining the saturation line by Polyfit interpolation and identifying the inflection point by taking the second derivative of the resistivity curve as described in Section 3.1.2 we have the following results:

$\checkmark$ The survey results by AMES method on line DMAT1 is shown in Figure 1.

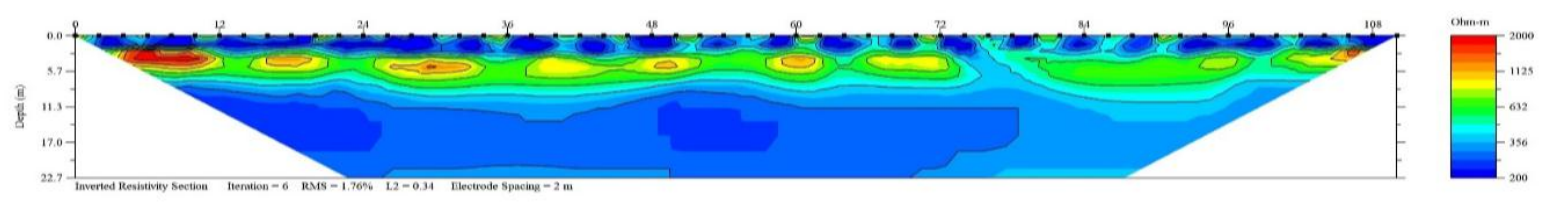

Fig 1. Results of 2D images on line DMAT [2]. 

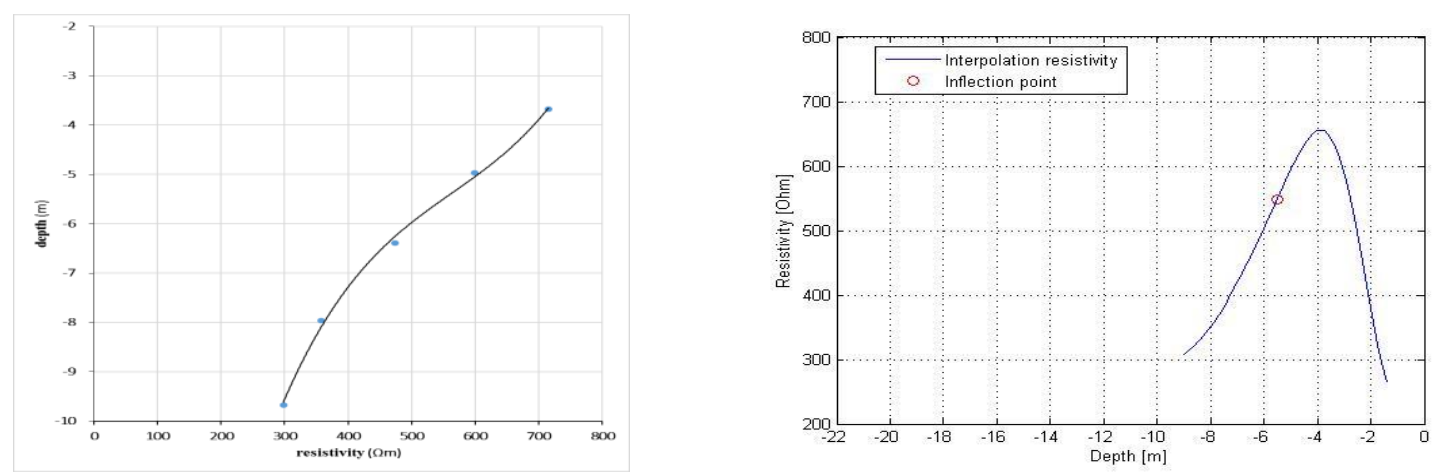

Fig 2. The resistivity curve at the position of $54,5 \mathrm{~m}$ on line DMAT1 using Trendline [2].

Fig 3. The resistivity curve at the position of $54,5 \mathrm{~m}$ on line DMAT1 using Polyfit interpolation.

Results using Trendline determines inflection point at the depth of $5,38 \mathrm{~m}$ with resistivity value of $563 \Omega \mathrm{m}$.

Results using Polyfit interpolation determines inflection point at the depth of $5,52 \mathrm{~m}$ with resistivity value of $547 \Omega \mathrm{m}$.

$\checkmark$ The survey results by AMES method on line DMAT2 is shown in Figure 4.

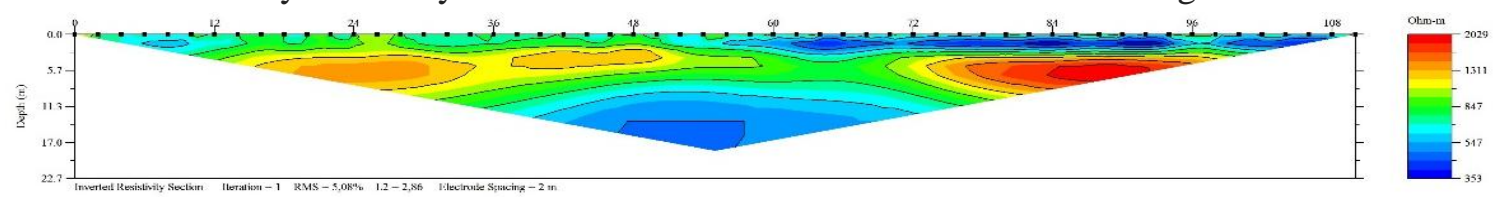

Fig 4. Results of 2D images on line DMAT2 [2].

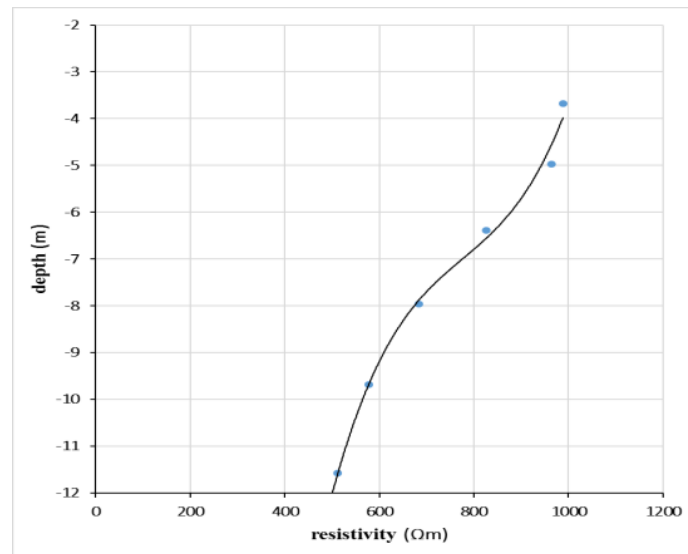

Fig 5. The resistivity curve at the position of $54,5 \mathrm{~m}$ on line DMAT2 using Trendline [2].

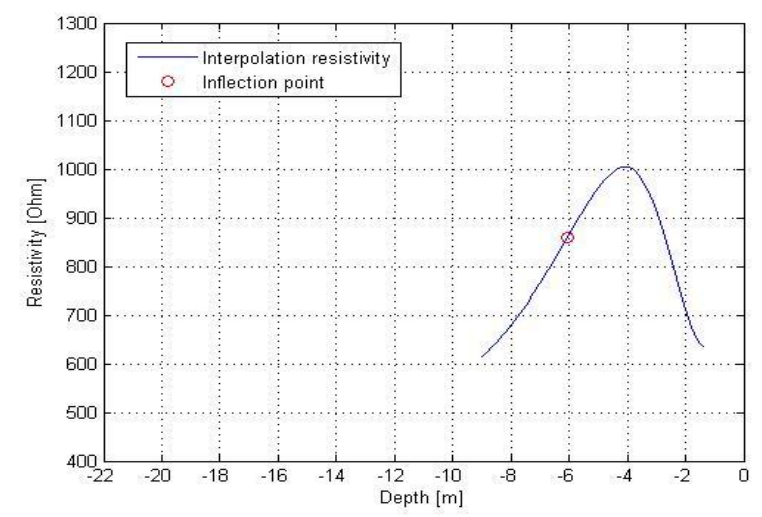

Fig 6. The resistivity curve at the position of $54,5 \mathrm{~m}$ on line DMAT2 using Polyfit interpolation.

Results using Trendline determines inflection point at the depth of $7,2 \mathrm{~m}$ with resistivity value of $761 \Omega \mathrm{m}$.

Results using Polyfit interpolation determines inflection point at the depth of $6,02 \mathrm{~m}$ with resistivity value of $858 \Omega \mathrm{m}$. 


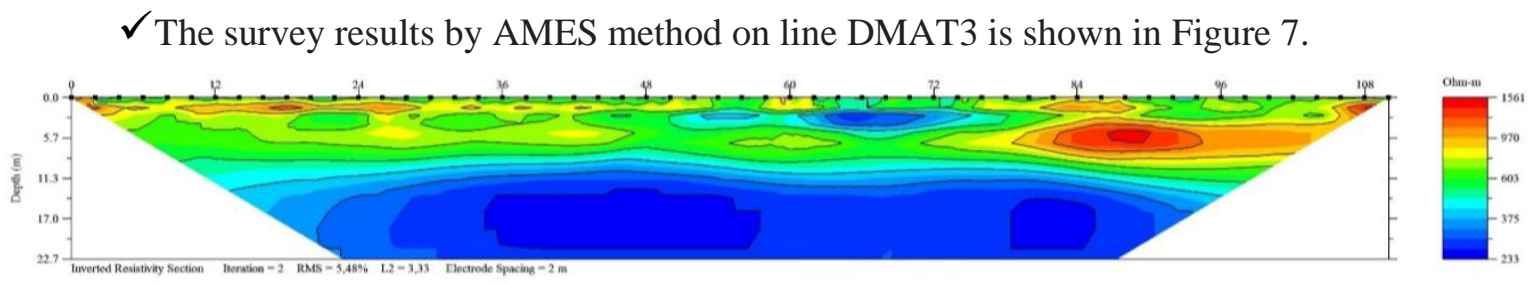

Fig 7. Results of 2D images on line DMAT3 [2].

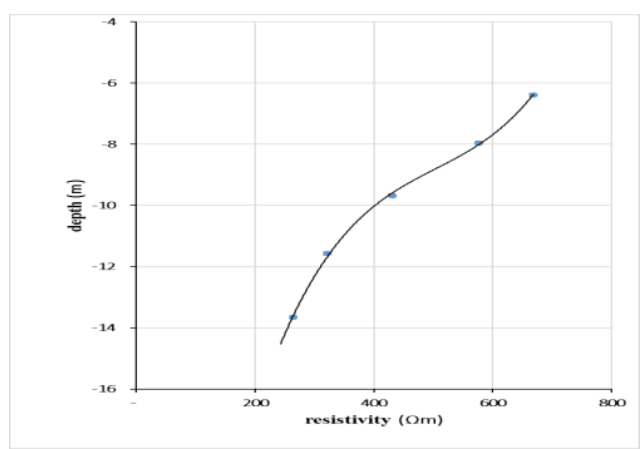

Fig 8 . The resistivity curve at the position of $54,5 \mathrm{~m}$ on line DMAT3 using Trendline [2].

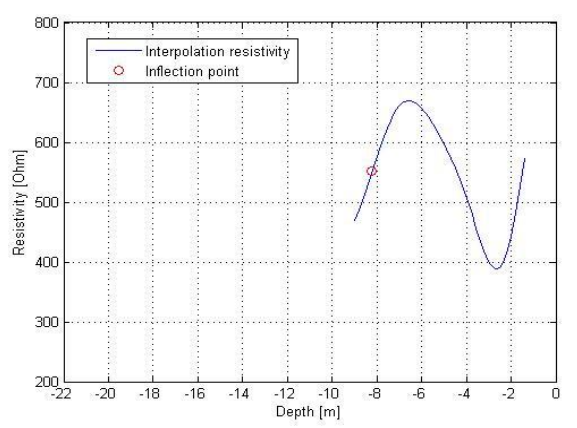

Fig 9. The resistivity curve at the position $54,5 \mathrm{~m}$ of on line DMAT3 using Polyfit interpolation.

Results using Trendline determines inflection point at the depth of $8,54 \mathrm{~m}$ with resistivity value of $495 \Omega \mathrm{m}$.

Results using Polyfit interpolation determines inflection point at the depth of $8,2 \mathrm{~m}$ with resistivity value of $551 \Omega \mathrm{m}$.

$\checkmark$ The survey results by AMES method on line DMAT4 is shown in Figure 10.

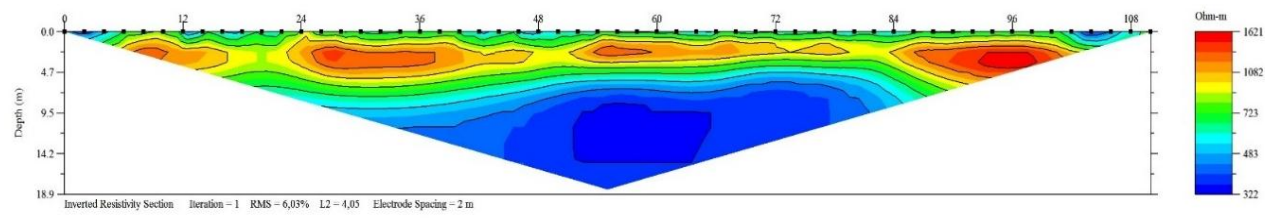

Fig 10. Results of 2D images on line DMAT4 [2].

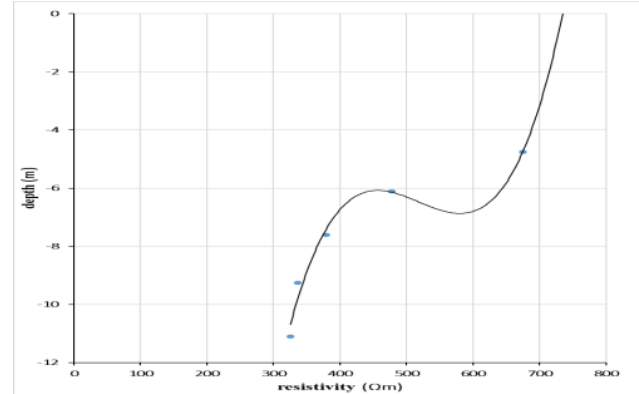

Fig 11 . The resistivity curve at the position of $54,5 \mathrm{~m}$ on line DMAT4 using Trendline [2].

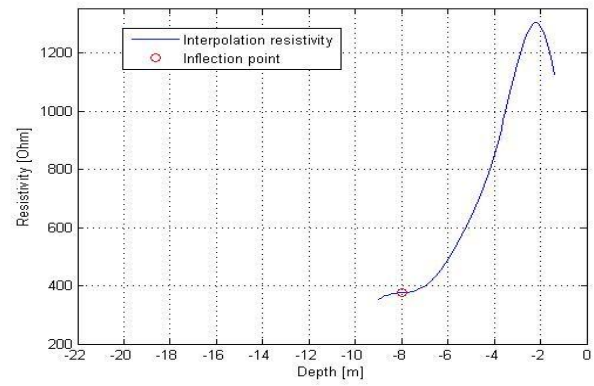

Fig 12 . The resistivity curve at the position of $54,5 \mathrm{~m}$ on line DMAT4 using Polyfit interpolation. 
Results using Trendline determines inflection point at the depth of $6.5 \mathrm{~m}$ with resistivity value of $528 \Omega \mathrm{m}$.

Results using Polyfit interpolation determines inflection point at the depth of 7,9m with resistivity value of $375 \Omega \mathrm{m}$.

$\checkmark$ The survey results by AMES method on line DMAT5 is shown in Figure 13.

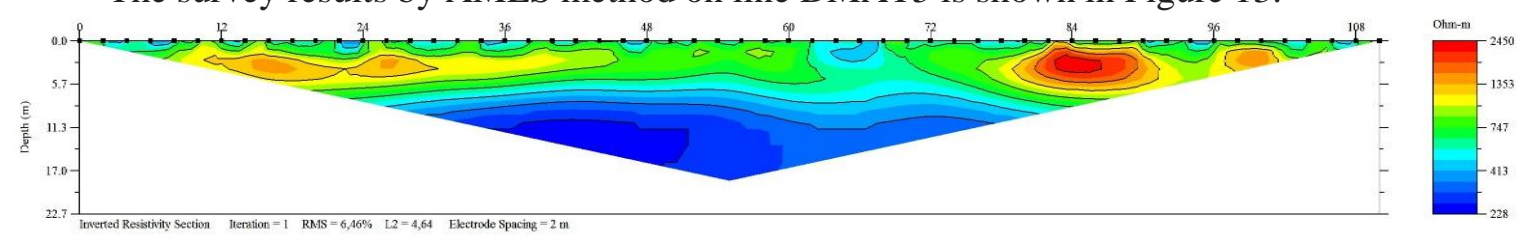

Fig 13. Results of 2D images on line DMAT5 [2].

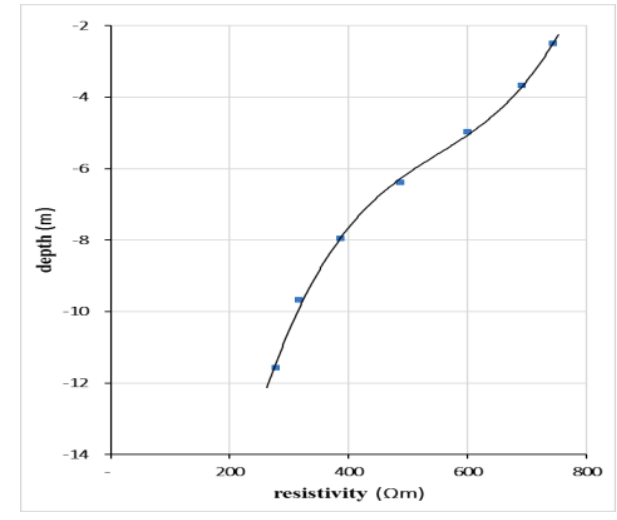

Fig 14. The resistivity curve at the position of $54,5 \mathrm{~m}$ on line DMAT5 using Trendline [2].

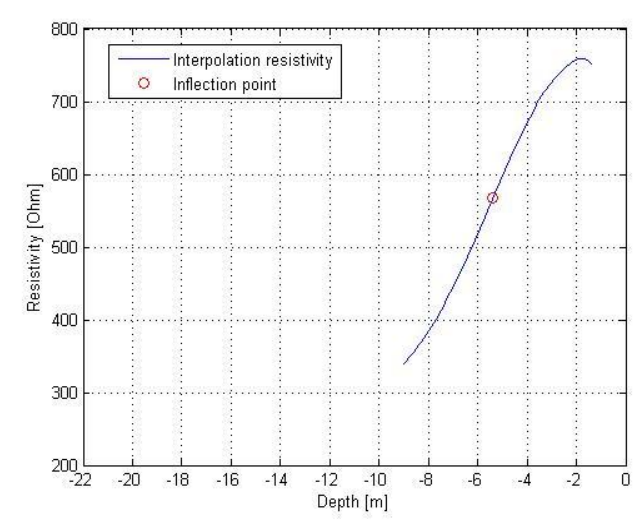

Fig 15. The resistivity curve at the position of $54,5 \mathrm{~m}$ on line DMAT5 using Polyfit interpolation.

Results using Trendline determines inflection point at the depth of $5,3 \mathrm{~m}$ with resistivity value of $545 \Omega \mathrm{m}$.

Results using Polyfit interpolation determines inflection point at the depth of 5,38m with resistivity value of $567 \Omega \mathrm{m}$.

$\checkmark \quad$ The survey results by AMES method on line the horizontal line is shown in Figure 16.

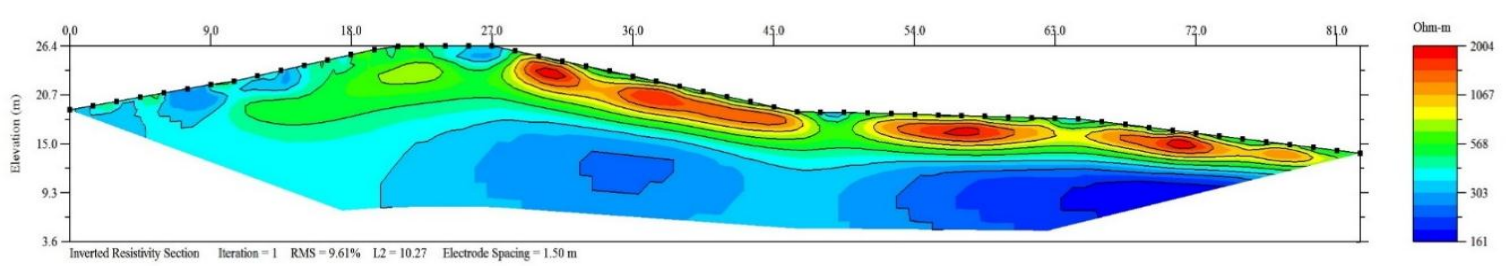

Fig 16. Results of 2D images on line the horizontal line [2].

Through the results of the above analysis and processing, we identified saturation line in Dong Mo dam by three methods, as shown in Table 1 and Figure 17. 
Table 1. The saturation line in Dong Mo dam

\begin{tabular}{cccccc}
\hline & & \multicolumn{5}{c}{ Elevation $(\mathrm{m})$} \\
\cline { 2 - 6 } No. & $\begin{array}{c}\text { Distance } \\
(\mathrm{m})\end{array}$ & Dam body & $\begin{array}{c}\text { Saturation line by } \\
\text { pizomet }\end{array}$ & $\begin{array}{c}\text { Saturation line by } \\
\text { Trendline }\end{array}$ & $\begin{array}{c}\text { Saturation } \\
\text { line by Profit } \\
\text { interpolation }\end{array}$ \\
\hline 1 & 0 & 18,95 & 18,95 & 18,95 & 18,95 \\
2 & 10,5 & 22,5 & & 17,12 & 16,98 \\
3 & 19 & 25,7 & & 18,5 & 19,68 \\
4 & 20 & 26,2 & 18 & & \\
5 & 26 & 26,4 & 17,4 & 17,36 & 15 \\
6 & 28 & 25,9 & & 16,4 & \\
7 & 36 & 22,9 & & & 13,22 \\
8 & 38 & 22,1 & 15,4 & & \\
9 & 49,5 & 18,67 & 13,97 & & 13,3 \\
10 & 51,5 & 18,6 & & & \\
\hline
\end{tabular}

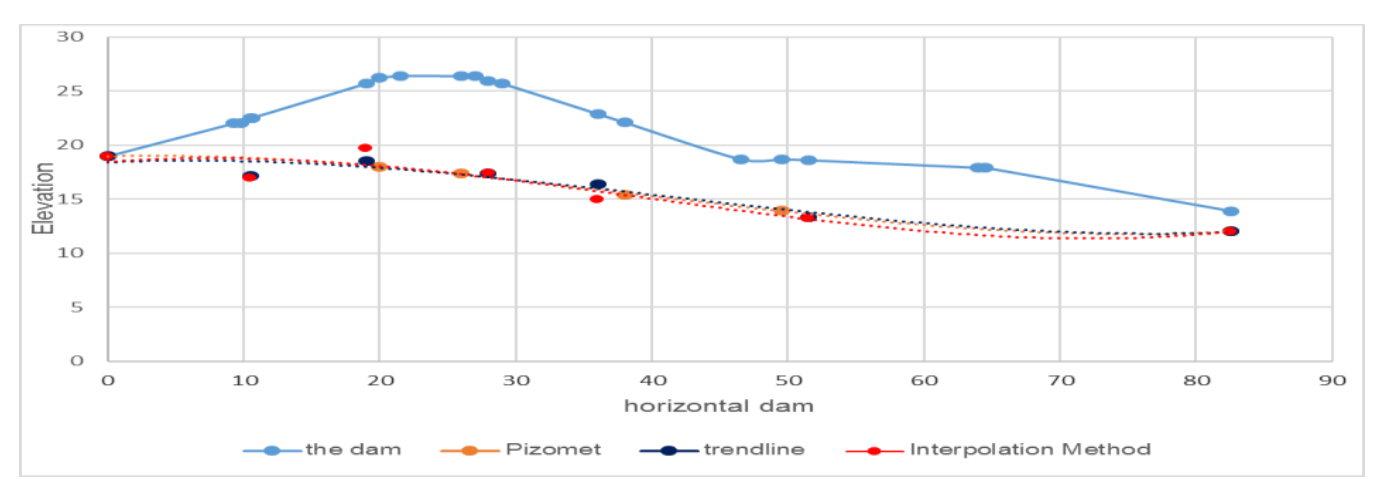

Fig 17. Map of the saturation line in Dong Mo dam.

To evaluate the error between the real saturation line measured by Pizomet and the saturation line determined by Trendline, we have to correct the saturation line determined by Trendline in term of the approximate location of the Pizomet pipes. In order to do so, from the results of determining saturation line by Trendline and measuring directly through the Pizomet (Table 1), we construct a trend curve (Figure 17) of the saturation line in the dam. From the trend curve equation, using the values of the Pizomet pipes' positions helps determine the depth and the elevation of saturation line at the aforementioned positions of Pizomet pipe (Table 2).

Table 2. The comparison results identified by Pizomet and by Trendline

\begin{tabular}{lllllll}
\hline \multirow{2}{*}{ No. } & \multicolumn{2}{l}{ Elevation $(\mathrm{m})$} & & Depth $(\mathrm{m})$ & $\begin{array}{l}\text { Difference } \\
(\mathrm{m})\end{array}$ & Error $(\%)$ \\
\cline { 2 - 5 } & Dam body & $\begin{array}{l}\text { Saturation line by } \\
\text { Pizomet }\end{array}$ & $\begin{array}{l}\text { Saturation line by } \\
\text { Trendline }\end{array}$ & & \\
\hline 1 & 26,2 & 18 & 18,25 & 8,2 & 0,25 & 3 \\
2 & 26,4 & 17,4 & 17,60 & 9,0 & 0,2 & 2 \\
3 & 22,1 & 15,4 & 16,00 & 6,7 & 0,6 & 9 \\
4 & 18,67 & 13,97 & 13,70 & 4,7 & 0,27 & 6 \\
\hline
\end{tabular}


From comparing between the results of determining the saturation line by $2 \mathrm{D}$ images with the results by Pizomet showed error of 2D images on Dong Mo dam at the maximum of about 9\%.

To evaluate the error between the real saturation line measured by Pizomet and the saturation line determined by Polyfit, we have to correct the saturation line determined by Polyfit in term of the approximate location of the Pizomet pipes. In order to do so, from the results of determining saturation line by Polyfit and measuring directly through the Pizomet (Table 1), we construct a trend curve (Figure 17) of the saturation line in the dam. From the trend curve equation, using the values of the Pizomet pipes' positions helps determine the depth and the elevation of saturation line at the aforementioned positions of Pizomet pipe (Table 3).

Table 3. The comparison results identified by Pizomet and by Polyfit

\begin{tabular}{lllllll}
\hline & \multicolumn{2}{l}{ Elevation $(\mathrm{m})$} & & & & \\
\cline { 2 - 4 } No. & Dam body & $\begin{array}{l}\text { Saturation line } \\
\text { by Pizomet }\end{array}$ & $\begin{array}{l}\text { Saturation line } \\
\text { by Profit } \\
\text { interpolation }\end{array}$ & $\begin{array}{l}\text { Depth } \\
(\mathrm{m})\end{array}$ & $\begin{array}{l}\text { Difference } \\
(\mathrm{m})\end{array}$ & $\begin{array}{l}\text { Error } \\
(\%)\end{array}$ \\
\hline 1 & 26,2 & 18 & 18,06 & 8,2 & 0,06 & 0.7 \\
2 & 26,4 & 17,4 & 17,31 & 9,0 & 0,09 & 1 \\
3 & 22,1 & 15,4 & 15,38 & 6,7 & 0,02 & 0.3 \\
4 & 18,67 & 13,97 & 13,73 & 4,7 & 0,24 & 5.1 \\
\hline
\end{tabular}

From comparing between the results of determining the saturation line by Polyfit interpolation method with the results by Pizomet showed error of Polyfit interpolation method on Dong Mo dam at the maximum of about $5.1 \%$.

\section{Discuss results}

- Our program with language Matlab for the chosen Polyfit interpolation method to determine the saturation line in earth dam by using second derivative to find the inflection point of the interpolation resistivity curve has contributed to the modules handling data processing of the AMES method.

- Practical application results from identifying saturation line in Dong Mo earth dam system by the AMES method using interpolation method are more accurate than the previous results with the biggest error of about $5.1 \%$ compared to results by Pizomet system.

- The AMES method using interpolation method can be fully applied to determine the saturation line in the earth dam better than the previous traditional methods, which once again confirms the possibility of applying the AMES method in the study of the environment in general and hazards in dams in particular.

- So far, the results from determining the saturation line by the AMES method has the biggest error of 5.1\% compared to the results determined by Pizomet system. This biggest error is at the position where the depth of saturation line is small $(4.7 \mathrm{~m})$. This is the issue that must continue to be further researched on, specifically on the distance of the electrode array.

- In order to further improve the accuracy of the obtained results, need to continue studying and improving data processing module according to the improved methods with the proposed new parameters, and at the same time conduct 3D measurements and processing. We will continue gradually perfecting AMES method to apply in practice the most effectively and announce better results in the future. 


\section{Acknowledgements}

We would like to convey our most sincere thanks to VNU - Asia Research Center for supporting the project and Department of Physics of Earth, Faculty of Physics, VNU University of Science for supporting the SuperSting R8/IP (USA), through which we can obtain the results presented in this paper.

\section{References}

[1] Vu Duc Minh, Do Anh Chung, "Introduction to the Advanced Multi-electrode Electrical Sounding method", VNU. Journal of Mathematics-Physics, 31(3), 2015, 1-14.

[2] Vu Duc Minh, Do Anh Chung, "Some experiment results of determining saturation line in Dong Mo dam by the Advanced Multi-electrode Electrical Sounding Method", VNU. Journal of Science, Natural Sciences and Technology, 31(3), 2015, 23-37. (Vietnamese)

[3] Phan Thi Ha, Phan Dang Cau, "Numerical methods", Posts and Telecommunications Institute of Technology, 2008. (Vietnamese)

[4] Ta Van Dinh, "Calculation method", Education Publisher, 1999. (Vietnamese)

[5] Advanced Geosciences, "The SuperSting ${ }^{\mathrm{TM}}$ with Swift ${ }^{\mathrm{TM}}$ automatic resistivity and IP system Instruction Manual", Advanced Geosciences Inc., Austin, Texas, 2000-2009.

[6] Advanced Geosciences, "EarthImager 2D resistivity and IP Inversion", Advanced Geosciences Inc., Austin, Texas, 2002. 